\title{
Finite Element Simulation and Experimental Investigation of Hot Embossing of Thin Polymer Film
}

\author{
Mohamed Sahli ${ }^{1, \mathrm{a}}$, Thierry Barrière ${ }^{1}$, Jean-Claude Gelin ${ }^{1}$ \\ ${ }^{1}$ Femto-st Institute, Applied Mechanics dept., CNRS UMR 6174, ENSMM, 25030 Besancon, France
}

Received 25 January 2010, Accepted 25 March 2010

\begin{abstract}
The modelling of the hot embossing process requires accurate determination of the polymer flows. The present work is focussed on experiments and numerical simulations of the hot embossing processes consisting in the replication of polymers plates on engraved shapes in the metallic plates that are used for the tests. In the proposed analysis consisting of the micro-indentation of the polymer plate, axisymmetrical and 2D FE models are used to analyse the cavity filling capabilities vs. strain rates, strains and temperature contours. The numerical simulation results show that profile deformation is largely influenced by the forming pressure and temperature, velocity of movement of upper plate and fluidity of the polymer during the embossing step. These results showed also the flow behaviour of COC inside the mould during hot embossing process. This may assist future improvement of manufacturing quality and production throughput. Hot embossing experiments were also conducted and the results obtained were compared with the simulated ones. The predicted workpiece geometry shows good agreement with experimental result. It is found that the finite element simulation results are in reasonable agreement with the experimental observation.
\end{abstract}

Key words: Hot embossing, Flow behavior, Simulation, Polymers

\section{Introduction}

Hot embossing is becoming a key technology to manufacture high precision and high quality plastic microstructures, using a range of thermoplastic polymers including PMMA, polycarbonate and cellulose acetate [1-4], Fig. 1. It provides several advantages such as low-cost for moulds, high replication accuracy for micro-features and simple operation [5,6]. This process include three steps, the first one consists in heating and applying pressure step, the second is remaining temperature and pressure step and the third one consists in demoulding step. The important parameters that govern the success of hot embossing process include temperature (usually heating the polymer substrate to above its glass transition temperature $\mathrm{T}_{\mathrm{g}}$, is required), pressure and embossing time. The protocol associated with this technology, as shows in Fig. 2; need to guarantee both the dimensional accuracy, even for complex shapes and replication of topographical surface states [7]. Numerous of studies have been conducted in recent years to investigate the hot embossing process for micro or nanostructures. The pressure profiles on the surface of the polymer during hot embossing process have been investigated. The results indicate that a higher embossing pressure results in more uniform shrinkage in the elastically deformed state during cooling [8].

Chang and Yang [9] reported an innovative method for hot embossing by applying gas pressure directly to press the mould and the substrate. This can improve replication accuracy because more uniform embossing pressure was applied across the entire substrate. Becker and Heim also concluded some suggestions in processing conditions for the hot embossing of polymer parts with micro-sized features [10].
Li et al. [12] carried out a series of experiments to investigate the processing of micro-components by hot embossing. The results indicate that the replication accuracy strongly depends on the processing conditions, in particular on the processing temperature and pressure.

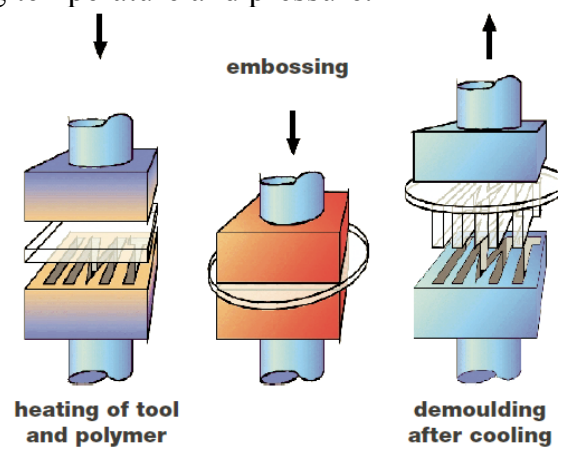

Fig. 1. Principle scheme of the hot embossing process [7]

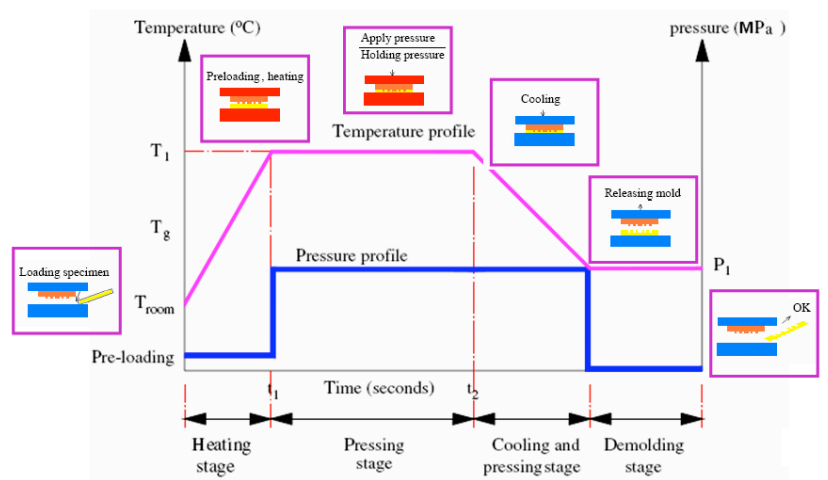

Fig. 2. Experimental setup of micro hot-embossing process [11]

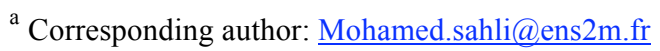


However, to date, only a limited number of contributions are focussed in numerical analysis concerning the forming by the hot embossing process in the mould cavity. Recently, Wang et al. [13] studied the hot embossing of forming microgear with $\mathrm{Zr}-\mathrm{Cu}-\mathrm{Ni}$-Al bulk metallic glass was analyzed by the finite element simulation with Deform 3D software and they report also experimental investigations. It was found that the finite element simulation results were in reasonable agreement with the experimental observations.

Chang et al. [14] studied the micro-imprinting replications using the finite element simulation method. In this study, they consider the viscous flow behaviour of the metallic and the amorphous polymer PMMA at temperatures slightly above their glass transition temperature. The result reveals that pressure level of $400 \mathrm{kPa}$ and forming time equal $4 \mathrm{~min}$ are good combinations to replicate micro-lens array. The results were in reasonable agreement with the experimental observation.

In this study, the finite element method has been used to perform modelling of hot embossing process using the LsDyna $^{\circledR}$ software in order to describe the behaviour of polymers plate during the forming process. A mechanical characterization of a COC polymer material by tensile tests was conducted at temperatures close to the glass transition temperature $\left(\mathrm{T}_{\mathrm{g}}\right)$ to assess to the behaviour of the polymer as a function of strain, strain rate and temperature. Then the results were considered to identify the material model that is used for the numerical simulations based on the finite elements method using the LsDyna ${ }^{\circledR}$ software.

\section{Finite elements model}

\subsection{Constitutive relations}

In 1983, Johnson and Cook $[15,16]$ proposed a constitutive model for materials which captures the strain rate and temperature dependency of the material, expression in the following form:

$$
\left.\sigma_{y}=\left[A+B\left(\varepsilon_{e f f_{y}}^{p}\right)\right] 1+C \ln \dot{\varepsilon}\right)\left[1-\left(T_{H}\right)^{n}-\right.
$$

where $\sigma$ is the the true stress, $A$ is the yield stress at room temperature and reference strain rate, $B$ is the strain hardening coefficient, $n$ is the strain hardening exponent, $\varepsilon$ is the plastic strain, $\dot{\varepsilon}$ is the plastic strain rate and $\mathrm{T}_{\mathrm{H}}$ is the homologous temperature and expressed as:

$$
T_{H}=T-T_{\text {room }} / T_{\text {melt }}-T_{\text {room }}
$$

with $T$ standing for the current absolute temperature, $T_{\text {melt }}$ the melting temperature and $T_{\text {room }}$ is the ambient temperature $\left(T \geq T_{\text {room }}\right)$. The minimum temperature of the matrix is taken as the reference temperature. Here it is limited to the interval $0 \leq \mathrm{T}_{\mathrm{H}} \leq 1$.

In Eq. (1) the terms within the first set of parentheses imposes a power-law relationship on the true stress versus effective plastic strain. The second term in parentheses introduces a logarithmic dependence on strain-rate. The final term gives the stress an exponential decay as temperature increases.

\subsection{Finite elements method}

With the data obtained through tensile test experiments, the simulation of hot embossing on COC polymers has been carried out with LsDyna. Fig. 3a illustrates the geometry, dimensions and boundary conditions of hot embossing, in which a circular shaped die is used. The initial FE mesh of the polymer part and the die mould are shown in Fig. $3 b$. Under the assumption of plain-strain forming conditions, FE results of the material flow and displacement contours on the polymer plate have been obtained. Moreover due to symmetry, only the right part of the system was considered. Other assumptions are proposed to describe boundary conditions. First of all, one considers that the polymer material exhibits a viscoplastic behaviour and the die mould remains rigid and not deformable. The mesh of the polymer plate and die mould were respectively composed of 4016, 300 and 1898 elements. It is assumed that the friction with the contact surfaces between polymer plate and die mould meet Coulomb friction law and remains unchanged during hot embossing process $(\mathrm{f}=0.1)$. The speed of upper die varies from 10 to $40 \mathrm{~mm} / \mathrm{s}$ (in steps of 10) and is kept constant during the simulation. A uniform mesh with an adaptive remeshing and hourglass control are employed to reduce the distortion of the elements and control the zero energy modes.
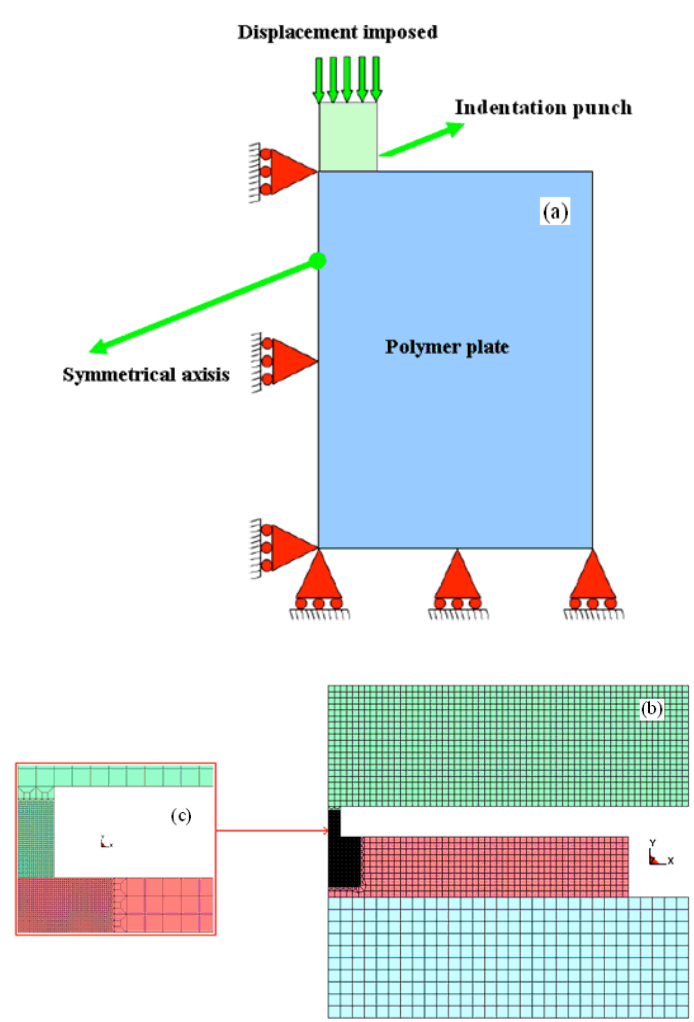

(a) Geometry and boundary

(b) Complete mesh conditions

(c) Zoom close to contact

Fig. 3. Finite element model used for the numerical simulations of hot embossing

\section{Experimental method}

\subsection{Materials}

In this analysis, COC in plate shape provided by Ticona ${ }^{\circledR}$ Company was used as substrate. It is a glassy polymer at room temperature, with a melt flow index between 14 and 
$48 \mathrm{~g} / 10 \mathrm{~min}$ as determined under a constant load of $2.16 \mathrm{~kg}$. The glass transition temperature of COC provided by supplier is about $130-140^{\circ} \mathrm{C}$. Each substrate with a thickness of $1 \mathrm{~mm}$ was cut to $20 \mathrm{~mm} \times 20 \mathrm{~mm}$ square pieces. The details of the mechanical and thermal properties of the considered materials are listed in Table 1.

Table 1. Main characteristics of the COC polymers

\begin{tabular}{lcc}
\hline Polymers grades & COC & COC \\
\hline Density & 1.02 & 1.02 \\
Young modulus $(\mathrm{MPa})$ & 3220 & 2900 \\
Glass transition temperature $\left({ }^{\circ} \mathrm{C}\right)$ & 140 & 135 \\
$\begin{array}{l}\text { Poisson's ratio } \\
\begin{array}{l}\text { Coefficient of linear thermal expansion } \\
\left(\mathrm{x} 10^{-4} \mathrm{~K}^{-1}\right)\end{array}\end{array}$ & 0.40 & 0.40 \\
\begin{tabular}{l} 
Thermal conductivity $(\mathrm{W} / \mathrm{mK})$ \\
\hline
\end{tabular} & 0.15 & 0.60 \\
\hline
\end{tabular}

\subsection{Method}

Instrumented compression tests reproducing the hot embossing process were conducted. For this analysis, the upper plate of a tensile test machine was equipped with a mould that includes a symmetric punch of cylindrical shape and with dimensions respectively equal to $\varnothing=200 \mu \mathrm{m}$ et $\mathrm{h}=800 \mu \mathrm{m}$ (depicted in Fig. 4). The speed varied from 10 to $40 \mathrm{~mm} / \mathrm{s}$ is kept constant during the tests. The material part used in this study is a plate of amorphous polymer of cyclo-olefincopolymer (COC), which was heated to a temperature close to the glass transition one $\left(\mathrm{T}_{\mathrm{g}}+20^{\circ} \mathrm{C}\right)$.

The experimental data associated to the geometry produced by the indentor and on the negative shape corresponding to a cavity in the polymer was conducted by scanning mechanical microscopy using an apparatus that was developed in our laboratory $[17,18]$. The comparative profiles related to areas with an identical location were performed using $\mathrm{N}=5000$ sampled points, equidistant with a value equal of $\mathrm{p}=2 \mu \mathrm{m}$, that represents a sampled total length of $\mathrm{L}=\mathrm{Np}=10 \mathrm{~mm}$. The correlation between the numerical data and the experimental ones enables to adopt a deformation model to the hot embossing process.

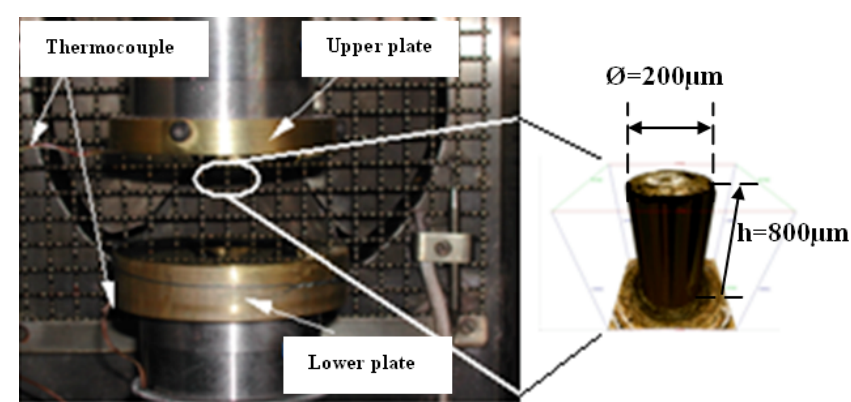

Fig. 4. Experimental set-up with the instrumented compression machine used for the tests

\subsection{Identification of material model parameters}

An experimental investigation on COC test tensile specimens subjected to tensile tests has been carried out. The cyclo-olefin copolymer has been first polymer injected in the cold room die mould in order to obtain the tensile test specimen with a hydraulic injection moulding equipment. The filling of the mould cavity was optimized at injection temperature and pressure equal to $260^{\circ} \mathrm{C}$ and between $10 \mathrm{MPa}$ respectively. Than, the tensile tests were performed on an Instron 6025 testing electrical equipment operating with axial speed control $(1 \mathrm{~mm} / \mathrm{min})$. The equipment is instrumented with an isothermal enclosure providing test temperatures from 20 to $300^{\circ} \mathrm{C}$ with $\pm 2 \%$ temperature regulation accuracy. Four temperatures have been tested: 100, 120, 140 and $160^{\circ} \mathrm{C}$. Two tensile strain rates for each temperature were used, ie. $10^{-3}$ and $10^{-1} \mathrm{~s}^{-1}$. The strain is measured using an extensometer positioned at the centre of the useful part of the tensile tests for temperatures below $130^{\circ} \mathrm{C}$. For temperature above $130^{\circ} \mathrm{C}$ for which the specimen becomes too extendable, the deformation was obtained as a function of the cross beam displacement. These experimental results were used to identification of constitutive material model parameters. A schematic view of the experimental setup is shown in Fig. 5.

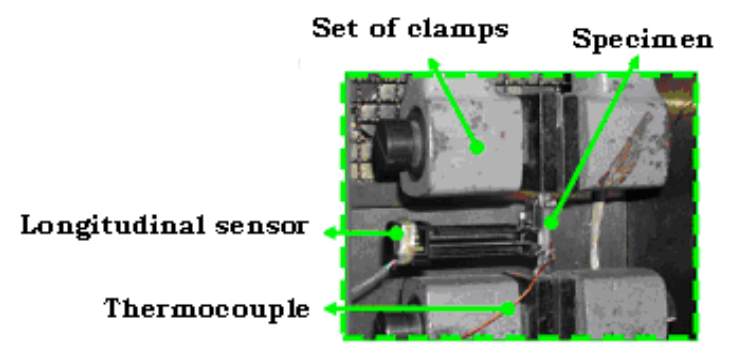

(a) Testing setup

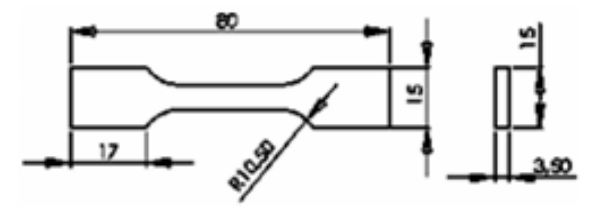

(b) Size and dimensions of the tensile tests specimens

Fig. 5. Experimental set-up for the tensile tests

Table 2. Material parameters corresponding to follow stress over of the COC

\begin{tabular}{ccc}
\hline & COC 5013 & COC 6013 \\
\hline$\dot{\varepsilon}$ & $10^{-3}$ & $10^{-3}$ \\
$\mathrm{n}$ & 0.27 & 0.25 \\
$\mathrm{~m}$ & 0.70 & 0.70 \\
$\mathrm{~A}$ & 0.45 & 0.20 \\
$\mathrm{~B}$ & 1.10 & 0.80 \\
$\mathrm{C}$ & 0.27 & 0.35 \\
\hline
\end{tabular}

The mechanical data recorded during the tensile test make it possible to derive the stress/strain relationship. In the case of thermo-elastic polymers, the selected behaviour law takes into account the accumulated plastic deformation, the temperature and the deformation rate. The material parameters 
corresponding to the model are listed in Table 2. As an example, the stress versus strain curve of the specimens at $160^{\circ} \mathrm{C}$ is shown in Fig. 6. Fig. 6 reveals a proper agreement between the experimental results and numerical solutions for the principal stresses.

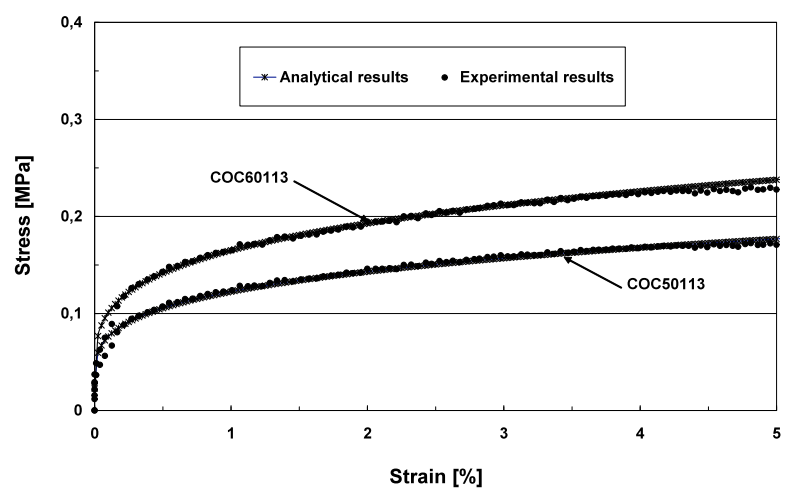

Fig. 6. Comparison of the flow stress curves obtained through tensile test specimens

\section{Results and discussions}

Fig. 7 shows the displacement contour in the polymer substrate during hot embossed. One can remark that during forming, the profile replication is associated with a correct filling. We remark again that the profile replication is consistent with expectations.

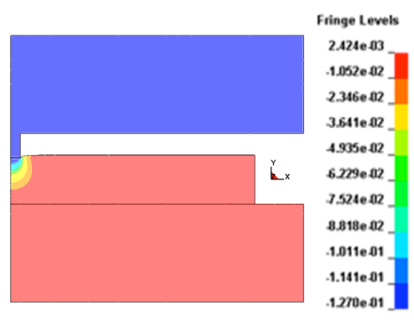

(a) $0.4 \mathrm{~ms}$

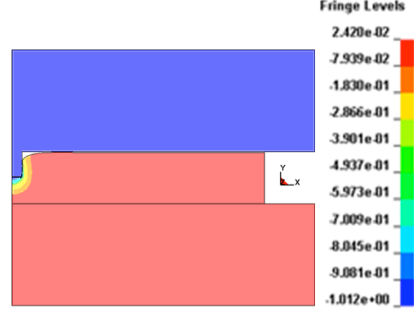

(c) $1.4 \mathrm{~ms}$

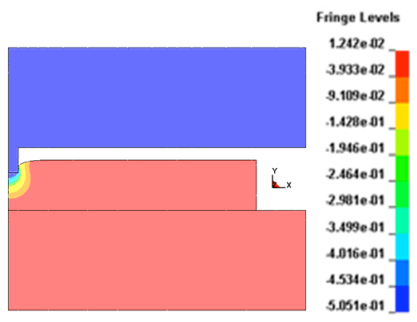

(b) $0.8 \mathrm{~ms}$

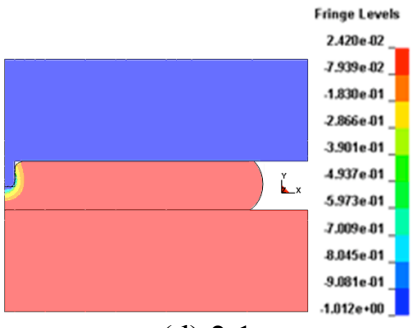

(d) $2.1 \mathrm{~ms}$
Fig. 7. Displacement contours obtained by FE simulation during hot embossing process at different instants

The graphs related in Fig. 8 reveal very similar trends for the deformed surface as a function of the imposed displacement. Moreover the appearance of visco-plastic polymer cushion increases continuously with the imposed displacement, which is linked to the sensitivity to strain rate in polymers. The area requested by the indenter is indeed greater when penetration increases.

Different simulations were carried out in order to optimize the forming parameter for hot embossing of polymer plate. Fig. 9 relates the variation of the value of the filling rate vs. the flow of viscoplastic polymers. One found that higher the melt flow is increased; the rate filling increases, leading thereby to replicas of the geometry shapes corres- ponds to the original. This Fig. shows off well the progressive filling of cavities that takes place in proper conditions. The filling of sharp edges of the cavities is more or less important almost equivalent linked to problems of material flow during the hot embossing process. One can notice that the trend is consistent with those ones reported in the literature.

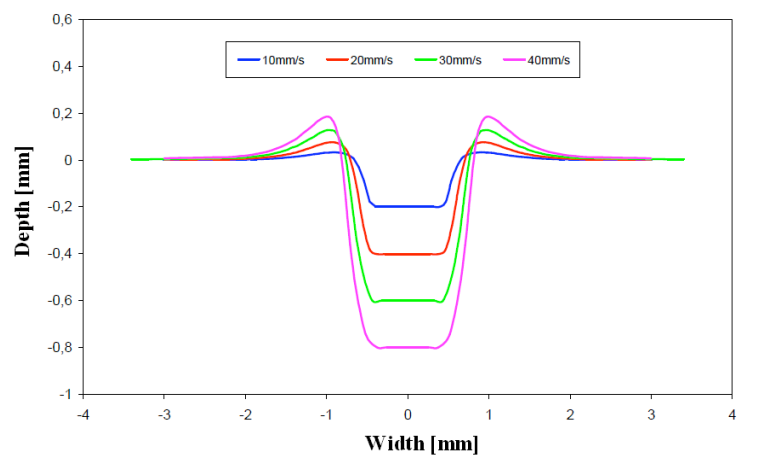

Fig. 8. Profiles of deformed surface obtained by indentation with the flat base cylindrical punch

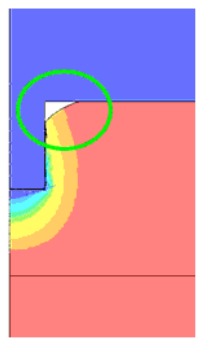

(a) $\mathrm{COC} 6013$

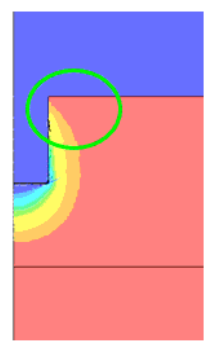

(b) COC 5013
Fig. 9. The filling of the mould cavity for different values of the imposed displacements

\section{Experimental validations}

The approach was reinforced by experimental studying the features of hollow imprints made by rigid indentation in the COC polymers plates. Fig. 10 reveals the fact that, the lower the young's modulus of the polymer, the deeper the imprint within is moreover, the temperature more increases with increasing depth.

The profiles of COC replications are related in Fig. 11. The curves related indicate that the responses obtained using this numerical model is rather similar to the experimental responses. The main difference take place in the part that is closes to the surface. These results help to understand and analysis the various observations resulting from the shaping of thermoplastic polymers using hot embossing.

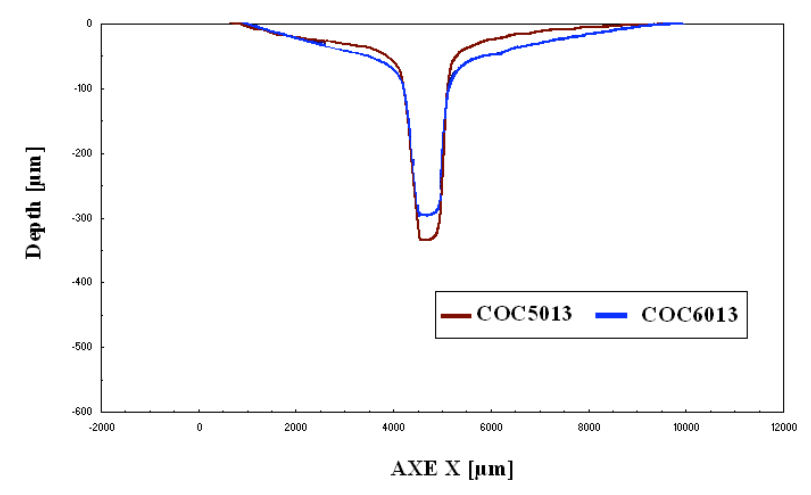

(a) Different polymers 


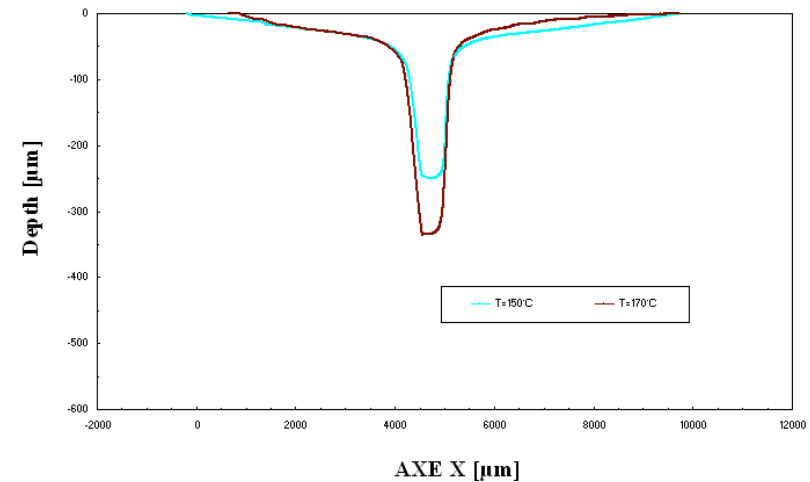

(b) COC 5013 at different temperatures

Fig. 10. Profile of deformed surface under a constant pressure

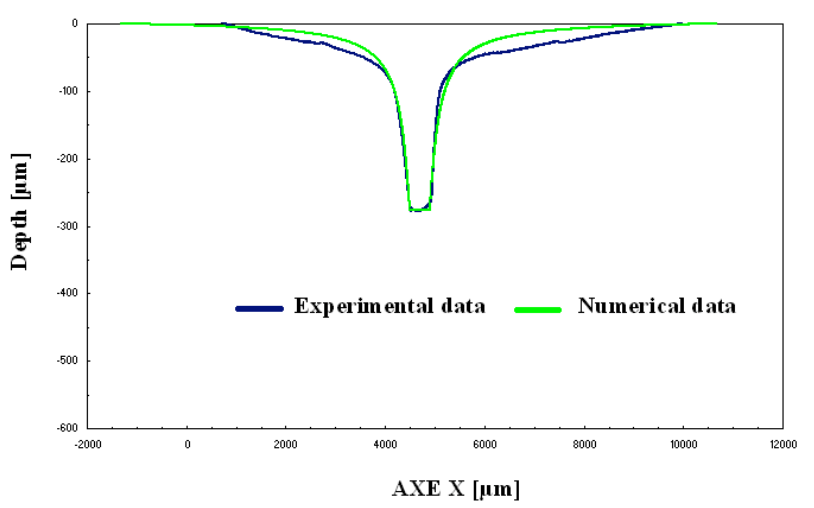

(a)

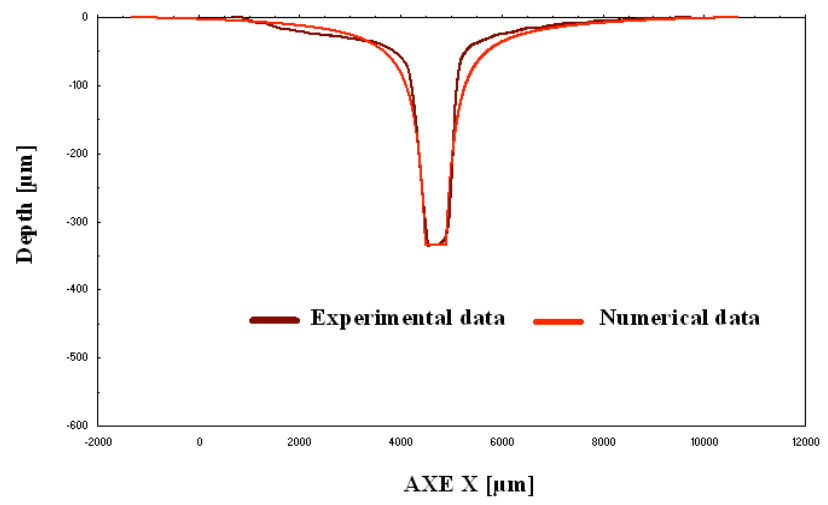

(b)

Fig. 11. Comparison between experimental results and modelling of the deformation of the surface under a constant pressure

\section{Conclusions}

This study focused on the numerical and experimental analysis concerning forming of polymers using hot embossing for the manufacturing of micro-components. In the proposed study, a simulation approach was developed based on a viscous model to analyze the polymer flow behaviour during the hot embossing process. Moreover, to have the proper conditions for replication, one has to know the polymer behaviour during the hot embossing process.

In the first part, the tensile tests are performed to identify the adequate material behaviour. The study consists in reproducing the uni-axial behaviour of the $\mathrm{COC}$ at $160^{\circ} \mathrm{C}$. One can confirm that the model parameters are well identified as the stress/strain profiles are reproduced correctly. In the second part, numerical simulations of hot embossing process were carried out integrating the physical and mechanical behaviour of the polymer as well as the conditions under which the forming process is conducted. Experimental validations of the numerical simulations are proposed. The results show that the calculated values vary in the same manner as the experimental data, and the agreement between the numerical model and the experimental results is good.

\section{References}

1. H. Becker, U. Heim. Hot embossing as amethod for the fabrication of polymer high aspect ratio structures. Sens. Actuators, 130-135, (2000).

2. M. Sahli, C. Millot, C. Roques-Carmes, C. Khan Malek, T. Barriere, J-C. Gelin. Quality assessment of polymer replication by hot embossing and micro-injection moulding processes using scanning mechanical microscopy. Journal of Materials Processing Technology, 5851-5861, (2009).

3. K. F. Leil, W. J. Li. Effects of contact-stress on hotembossed PMMA microchannel wall profile. Microsyst. Technol. 11, 113-119, (2005).

4. M. Sahli, C. Millot, C. Roques-Carmes, C. Khan Malek, T. Barrière, J-C. Gelin. Optimization of hot embossing demoulding for improvement of quality replication of circular grooved shapes in cycloolefin polymer. Steel Res. Int., 513-520, (2008).

5. Y. J. Huang, L. L. James. Hot embossing in microfabrication. Parte I. Experimental. Polym. Eng. Sci. 42, 539-550, (2002).

6. Y. J. Juang, L. L. James. Hot embossing in microfabrication II. Rheological characterization and process analysis. Polym. Eng. Sci. 42, 539-550, (2002).

7. M. Heckele, W. Bacher, K. D. Müller. Hot embossing: the moulding technique for plastic microstructures. Microsyst. Technol., 122-124, (1998).

8. C. R. Lin, R. H. Chen, C. Hung. Preventing non-uniform shrinkage in open-die hot embossing of PMMA microstructures. J. Mater. Process. Technol. 140, 173-178, (2003).

9. J. H. Chang, S. Y. Yang. Gas pressurized hot embossing for transcription of micro-features. Microsyst. Technol. 10, 76-80, (2003).

10. H. Becker, U. Heim. Hot embossing as a method for the fabrication of polymer high aspect ratio structures. Sensors and Actuators A 83, 130-135, (2000).

11. M. Sahli, C. Millot, C. Roques-Carmes, C. Khan Malek. Experimental analysis and numerical modelling of the forming process of polypropylene replicas of microcavities using hot embossing. Microsyst Technol, 827-83, (2009).

12. J. M. Li, C. Liu, J. Peng. Effect of hot embossing process parameters on polymer flow and microchannel accuracy produced without vacuum. Journal of materials processing technology 207, 163-171, (2008).

13. D. Wang, T. Shi, J. Pan, G. Liao, Z. Tang, L. Liu. Finite element simulation and experimental investigation of forming micro-gear with $\mathrm{Zr}-\mathrm{Cu}$-Ni-Al bulk metallic glass. Journal of Materials Processing Technology, 210, 684688, (2010).

14. Y. C. Chang, T. T. Wu, M. F. Chen, C. J. Lee, J. C. Huang, C. T. Pan. Finite element simulation of microimprinting in $\mathrm{Mg}-\mathrm{Cu}-\mathrm{Y}$ amorphous alloy. Materials Sci- 
ence and Engineering A 499, 153-156, (2009).

15. Y. C. Chang, T. T. Wu, M. F. Chen, C. J. Lee, J. C. Huang, C. T. Pan. Finite element simulation of microimprinting in $\mathrm{Mg}-\mathrm{Cu}-\mathrm{Y}$ amorphous alloy. Materials Science and Engineering A 499, 153-156, (2009).

16. G. R. Johnson, W. H. Cook. A constitutive model and data for metals subjected to large strains, high strainrates and high temperatures. Proc. $7^{\text {th }}$ Int. Symposium on Ballistics, 541-547, (1983).
17. G. R. Johnson, W. H. Cook. Fracture characteristics of three metals subjected to various strains, strain rates, temperatures and pressures. Engineering Fracture Mechanics 21, 31-48, (1985).

18. C. Roques-Carmes, N. Bodin, G. Monteil, J. F. Quiniou. Description of rough surfaces using conformal equivalent structure concept Part 1. Stereological approach. Wear 248, 82-91, (2001).

19. D. Wehbi, G. Monteil, C. Roques-Carmes. Notion de rugosité de surface et méthodes de mesure. Le vide, les couches minces 224, 107, (1985). 